\title{
JUÍZOS REFLEXIVOS TELEOLÓGICOS E SUA RELAÇÃO COM O SENTIMENTO DE PRAZER E DESPRAZER
}

\author{
Vera Cristina de Andrade BUENO ${ }^{1}$
}

- RESUMO: Depois de ter estabelecido uma conexão geral entre a faculdade do juízo e o sentimento de prazer e desprazer na "Primeira introdução" à Crítica da faculdade do juízo, Kant, na "Introdução publicada", restringe, gradativamente, essa conexão aos juízos estéticos e aos juízos que lidam com a sistematização da natureza. Essa restrição acaba por deixar os juízos teleológicos fora da conexão geral anteriormente estabelecida. O objetivo do artigo é propor os passos necessários para restabelecer a conexão entre os juízos teleológicos e o sentimento de prazer e desprazer, pois se trata de uma conexão, a princípio, supostamente válida para todos os juízos reflexionantes.

- PALAVRAS-CHAVE: Kant; juízo reflexivo; juízo teleológico; princípio de finalidade; sentimento de prazer e desprazer; ação moral.

\section{Introdução}

Na Introdução publicada à Crítica à faculdade do juízo, Kant propõe uma divisão da extensão do conceito de filosofia em filosofia teórica, possibilitada pela legislação do entendimento e filosofia prática, possibilitada pela legislação da razão. ${ }^{2}$ A faculdade do juízo seria a faculdade mediadora

1 É professora da Pontifícia Universidade Católica (PUC) do Rio de Janeiro.

2 A Crítica da faculdade do juízo (CFJ) tem duas Introduções, uma que foi publicada junto com a obra, referida como "Introdução publicada" e uma que foi publicada separadamente, referida como "Primeira introdução". As referências da Introdução publicada junto com a obra e as da própria obra aparecerão com as letras CFJ, seguidas do capítulo e parágrafo em que elas se encontram e da página da tradução feita para a língua portuguesa por Valério Rohden e Antonio Marques para a Editora Forense Universitária, Rio de Janeiro, 1993. A "Primeira introdução" foi traduzida para a 
entre as partes dessa divisão, pois ainda que ambas as legislações tenham domínios diferentes, ou seja, jurisdições, diferentes, elas têm, no entanto, um território comum, o território da experiência possível. É nesse território que as duas legislações se realizam e são exercitadas. A faculdade do juízo, por ser mediadora, diz respeito ao território comum àqueles dois domínios. Em função desse território comum, e na medida em que a legislação do entendimento não poderia estender-se para além do domínio da natureza, a possibilidade de se estabelecer um elo entre essas duas legislações teria de ser resgatada pela via da razão prática, na medida em que a razão prática em sua legislação produz efeitos no mundo da natureza. Para dar conta dessa possibilidade Kant propõe uma crítica da faculdade do juízo (CFJ: II, p. 18; AA 05:174-176).

Por sua vez, na Primeira Introdução, ao propor uma sistematização das faculdades, Kant circunscrevera a faculdade de sentir prazer e desprazer, como uma faculdade mediana, distinta tanto da faculdade de conhecimento (o entendimento) quanto da faculdade de desejar (a razão prática) e que tem seu fundamento na conexão a priori que as faculdades mantêm entre si. Em função desse fundamento, Kant propõe uma vinculação entre a faculdade de sentir prazer e desprazer e a faculdade do juízo (DI: III. p. 42-43; AA, 20:207).

De fato, não só nas Introduções, mas também na primeira parte da CFJ, Kant sustenta que o sentimento de prazer e desprazer é a condição necessária para a fundamentação dos juízos estéticos de gosto. Se a CFJ dissesse respeito apenas a esses juízos, não haveria nenhum problema na conexão entre a faculdade do juízo e o sentimento de prazer e desprazer. No entanto, no decorrer das Introduções e na segunda parte do livro, Kant atribui à faculdade do juízo, além da função estética, as funções lógica e teleológica. A função lógica dos juízos é necessária para a formação dos conceitos e leis empíricas e a teleológica para lidarmos de modo adequado com certos objetos na natureza, objetos que não podem ser considerados apenas em função da causalidade eficiente, a causalidade que rege a relação entre os fenômenos. Diante dessas especificações, Kant limita a conexão da faculdade do juízo com o sentimento de prazer aos juízos estéticos (CFJ: VIII, p.36-37; AA 05:193).

Além disso, na Introdução publicada, Kant estipula como o critério da divisão da CFJ - crítica da faculdade do juízo estética e crítica da faculdade do juízo teleológica - aquilo que serve de fundamento para cada uma des-

língua portuguesa por Rubens Torres Filho e se encontra no livro Duas introduções à Crítica do juízo (DI), editado por Ricardo Terra, para a Editora Iluminuras, São Paulo, 1995. Este livro contém também a Introdução publicada, traduzida por Carlos A. M. Novaes, H. Bornebusch, M. Suzuki, M.A. Novaes Filho e Ricardo Terra. As referências à "Primeira introdução" aparecerão com as letras DI (Duas Introduções) seguidas do número do capítulo e da página da tradução para a Editora Iluminuras. Todas as referências serão seguidas do volume e da página da Kants gesammelte Schriften, Herausgegeben von der Königlich Preussien Akademie der Wissenschaften (AA). 
sas faculdades: o sentimento de prazer e desprazer para a faculdade do juízo estética e os conceitos da razão e do entendimento para a faculdade do juízo teleológica (CFJ: VIII,p.37; AA 05:193). Ao negar a conexão entre os juízos teleológicos e o sentimento de prazer e desprazer, Kant coloca o leitor diante de uma situação semelhante a uma antinomia, na qual que o que seria uma proposição particular negativa - a negação da conexão entre os juízos teleológicos e o sentimento de prazer e desprazer -, contradiz o que seria uma universal afirmativa - a afirmação de que a faculdade do juízo tem uma conexão com o sentimento de prazer.

Pretendo, então, (1) analisar as razões pelas quais Kant propõe que a faculdade de sentir prazer e desprazer esteja em conexão como a faculdade do juízo em geral; (2) analisar as razões pelas Kant retira dos juízos teleológicos sua conexão com a faculdade de sentir prazer e desprazer; e (3) propor um caminho que torne possível restabelecer uma conexão entre a faculdade de sentir prazer e desprazer e o juízo teleológico, resgatando, desse modo, a proposta inicial de Kant ao tratar da sistematização das faculdades, ou seja, a conexão entre a faculdade de sentir prazer e desprazer e a faculdade do juízo em geral.

\section{O sentimento de prazer e desprazer e a faculdade do juízo}

A primeira pergunta que surge para dar conta dessa conexão é: o que teria levado Kant a relacionar a faculdade do juízo com a faculdade de sentir prazer e desprazer? Kant não nos deixa muito tempo sem resposta: o princípio de finalidade. Esse é o princípio que rege toda a CFJ. Na verdade, ele se encontra presente em toda a proposta crítica, mas começamos a notar sua presença de forma mais nítida no Apêndice à Dialética da Crítica da razão pura ${ }^{3}$ No Apêndice, ao retomar a proposta de investigar a extensão e os limites das faculdades humanas para saber como podemos usá-las de forma adequada, Kant diz: "o que se funda sobre a natureza de nossas faculdades tem de ser adequado a um fim e conforme com seu uso legítimo; trata-se apenas [nessa investigação] de ... descobrir a direção própria dessas faculdades" (CRP, A643/B671).

O princípio de finalidade é um princípio que tem origem na própria razão e que a orienta em suas atividades de modo a descobrir o seu uso correto. Kant propõe que vejamos a razão humana como um todo constituído por partes bem delimitadas em que cada uma delas desempenha um papel que lhe é próprio, de modo a que a razão possa dar conta de todas as ativi-

3 As citações referentes à Critica da razão pura foram extraídas da tradução para a língua portuguesa, feita por Manuela Pinto dos Santos e Alexandre Fradique Morujão. Lisboa: Fundação Calouste Gulbenkian, 1994. Elas serão feitas como de costume: A para a $1^{a}$. edição e B para a $2^{\mathrm{a}}$. De agora em diante usarei $C R P$ para me referir a essa obra. 
dades propriamente humanas: o conhecer, o agir e o sentir prazer e desprazer. Investigando a tradição, Kant se deu conta de que a razão, por sua própria natureza e sem a crítica, pretende conhecer o que está além do que é dado aos sentidos, pois ela tende a buscar o princípio último, a unidade suprema, de tudo aquilo que conhecemos na experiência. A razão tende, portanto, naturalmente a ultrapassar o conhecimento daquilo que é dado na experiência e a dirigir-se para o supra-sensível. O idealismo transcendental é o resultado de uma investigação da natureza da razão.

A crítica, guiada pelo princípio de finalidade, orienta a razão no sentido de trazê-la para aquilo em que ela pode desempenhar com sucesso na sua tarefa de busca de unidade: a sistematização dos conceitos empíricos que se encontram no entendimento. Desse modo, a tendência natural da razão para a unidade dá a esses conceitos a forma de uma ciência. ${ }^{4}$

No entanto, não há o menor sentido, diz Kant, sistematizar conceitos e pressupor que a natureza, onde os objetos correspondentes a esses conceitos se encontram, não possa também ser pensada de uma forma sistemática (CRP, A651/B679). Sistematizar os conceitos teria de ir de par com a possibilidade de formar conceitos e formar conceitos exige a pressuposição a priori de que a natureza não seja inteiramente heterogênea em seus produtos. Esse é um pressuposto transcendental, pois leva-nos a atribuir algo à natureza, não só uma afinidade entre seus produtos, mas também uma afinidade entre a natureza e as nossas faculdades cognitivas. ${ }^{5}$

Esse pressuposto, porém, não diz respeito à natureza em si, e sim a nós, para lidarmos com os objetos dados, pois, de acordo com a proposta do idealismo transcendental, não sabemos nada sobre a natureza em si; mas precisamos introduzir nela o pressuposto da homogeneidade entre seus produtos para que possamos lidar com a diversidade que manifestam. A validade desse princípio é, portanto, meramente subjetiva e necessária, se quisermos "conferir unidade aos conhecimentos particulares e aproximar assim a regra da universalidade" (CRP, A647/B675). É um princípio que permite nos aproximarmos da natureza de acordo com um fim: o de dar a ela uma forma sistemática. Como é um princípio que não constitui objeto algum, diferentemente do que acontece com os princípios do entendimento, ele não faz parte dos princípios chamados constitutivos. É um princípio que se funda na razão, e cujo uso é problemático, uma vez que o princípio vale como uma hipótese de trabalho e depende de nossas intenções relativa-

4 Segundo Kant, "a unidade sistemática é o que converte o conhecimento vulgar em ciência" (CRP, A832/B860)

5 Kant diz o seguinte a esse respeito: "na diversidade de uma experiência possível deverá supor-se, necessariamente, uma homogeneidade (embora não possamos determinar a priori o seu grau), porque, sem esta, não haveria mais conceitos empíricos, nem, por conseguinte, experiência possível" (CRP, A654/B682). 
mente aos objetos da natureza (CRP, A644/B672). Kant chama os princípios que têm esse caráter problemático, ou hipotético, de regulativos. $\mathrm{Na}$ Primeira Introdução à CFJ, Kant chama essa espécie de finalidade, que possibilita a formação de conceitos, dentre outras espécies de finalidade que têm uma função regulativa, de finalidade lógica (DI: VII, p.53; AA 20:217).

Se, quanto ao conteúdo, o pressuposto da homogeneidade é necessário para dar conta dos produtos da natureza, quanto à forma, os produtos precisam de outro pressuposto, o da natureza da faculdade do juízo ela mesma, na medida em que é de sua natureza pensar "o particular como contido no universal" (CFJ: IV, p.23; AA 05:179). Por meio da faculdade do juízo, que conecta o particular com o universal, a imaginação apreende os dados sensíveis e procura um universal para eles, a saber, um conceito pensado pelo entendimento, que daria unidade cognitiva a esses dados, isto é, que os completaria. Kant vê da seguinte maneira a relação entre faculdade do juízo e o princípio de finalidade: "em nosso juízo percebemos a finalidade, na medida em que ele [o juízo] meramente reflete sobre um objeto dado, ..., para trazê-la a um conceito qualquer (sem determinar qual) ..." (DI: VII, p.56; AA 20:220).

Por meio da faculdade do juízo é possível, então, pensar numa finalidade formal na natureza, pois, nesse caso, a forma dos objetos sensíveis é compatível com as nossas faculdades. Para o idealismo transcendental, nossas faculdades cognitivas também são formas puras, as quais determinam a natureza do nosso conhecimento. Ao levar em conta a compatibilidade possível entre a forma do objeto e as faculdades cognitivas humanas, Kant descobre a possibilidade de um fundamento a priori para o sentimento de prazer e desprazer, pois, ao apreender os objetos sensíveis, a imaginação e o entendimento se favorecerem mutuamente, gerando um sentimento, resultante do estímulo recíproco das faculdades entre si. O juízo que se funda nesse sentimento é o juízo estético de gosto.

A conexão entre a faculdade do juízo e a faculdade do sentimento de prazer tem, pois, como ponto de partida o princípio de finalidade da natureza e, como mediação, não só o acordo entre a forma do objeto apreendida por nossa imaginação, mas também o acordo recíproco entre a imaginação e o entendimento. Esse acordo recíproco é constitutivo da própria faculdade do juízo. O sentimento de prazer resultante desses acordos é, pois, possível pela relação entre o princípio de finalidade da natureza e a faculdade do juízo ela mesma. ${ }^{6}$

6 A relação entre a faculdade do juízo e o sentimento de prazer, que tem como princípio a finalidade da natureza, é proposta pela crítica dessa faculdade como aquela que "lhe é essencial, porque apenas esta [a crítica da faculdade do juízo estética] contém um princípio que a faculdade do juízo coloca como princípio inteiramente a priori na sua reflexão sobre a natureza, a saber, o princípio de uma finalidade a fins formal da natureza segundo as suas leis particulares (empíricas) para a nossa faculdade de conhecimento, conformidade sem a qual o entendimento não se orientaria naquelas" (CFJ: VIII, p. 37; AA 05:193). 


\section{Razões pelas quais os juízos teleológicos não teriam seu fundamento no sentimento de prazer e desprazer}

Ainda que Kant tenha conectado a faculdade do juízo em geral com a faculdade do sentimento de prazer, ele acaba limitando esse sentimento especialmente aos juízos estéticos, mas sem deixar de observar que a formação dos conceitos e leis empíricas e a reunião e integração de leis empíricas inferiores em superiores estão, também, conectadas com o sentimento de prazer. "A descoberta da possibilidade de união de duas ou várias leis da natureza empíricas, sob um princípio que integre ambas, é razão para um prazer digno de nota, muitas vezes até de admiração sem fim, ainda que o objeto deste nos seja bastante familiar" (CFJ: VI, p.31; AA 05: 187). Esse prazer é possível porque os juízos de reflexão lógicos e estéticos partem de objetos dados em que imaginação e entendimento são bem sucedidos em sua tarefa não só de formar leis empíricas a partir desses objetos, como também apreender a forma deles de modo a que essa apreensão, ligada ao entendimento, gere o sentimento de prazer. O conceito formado por meio dessa atividade tem uma ligação com o sentimento de prazer: seja porque esse sentimento antecede a formação do conceito, como acontece nos juízos de gosto, seja porque o sentimento sucede a formação do conceito como nos juízos lógicos.

Os juízos teleológicos, por sua vez, pressupõem um conceito, que possibilita que o objeto em questão seja visto como final. Não se trata aqui do pressuposto geral de que a natureza como um todo seja vista como final para nossas faculdades cognitivas, mas do fato de considerarmos certos objetos da natureza como sendo, eles mesmos, finais. O fundamento do juízo teleológico está, portanto, no conceito de fim que antecede esses objetos e determina a maneira de lidarmos com eles.

Mas, ainda que o juízo teleológico se distinga dos juízos lógicos e estéticos, por pressupor um conceito, ele tem em comum com esses juízos o fato de que o conceito que o determina não ser um conceito puro do entendimento. O conceito de fim não faz parte da forma lógica do entendimento. É um conceito problemático que, como dissemos, faz com que seu uso seja regulativo. Por ser problemático, não sabemos como ele se realizaria na natureza, e, nesse sentido, não podemos também saber que ação que o efetivaria. Como essa efetivação é problemática, o sentimento de prazer não poderia estar conectado com ele.

No entanto, se está claro que o juízo teleológico não se funda na faculdade de sentir prazer e desprazer, assim como está também claro que o conceito no qual ele se funda não é um conceito do entendimento, mas um conceito problemático da razão, nem por isso já está de todo claro que não é possível, de forma alguma, conectar esse juízo com o sentimento de prazer, 
pois não podemos nos esquecer de que Kant ligou a faculdade do juízo em geral com o sentimento de prazer e desprazer.

Apesar de todas as restrições feitas a esse juízo, concernentes à sua conexão com o sentimento de prazer, Kant parece, por alguma razão, querer mitigar essa restrição, pois na Introdução publicada, ele liga o sentimento de prazer à realização de uma intenção. "A realização de toda e qualquer intenção está ligada com o sentimento de prazer" (Idem, ibdem). Afirmar que a realização de toda intenção está ligada com o sentimento de prazer é, por um lado, trazer para discussão o conceito que veiculou a intenção; ter uma intenção é colocar algo como um fim, isto é, pressupor um conceito por meio do qual algo é visto como um fim; por sua vez, a efetivação desse fim gera prazer. Por outro lado, ter o conceito de um fim é a condição necessária para que um juízo seja qualificado de teleológico. Assim, se a intenção pensada é realizada e se a realização da intenção gera prazer, é sinal de que há uma conexão entre o conceito pensado e o prazer sentido. Como o que caracteriza o juízo teleológico é o conceito de fim que ele traz consigo, se tivermos um meio de relacionar a efetivação daquilo que está intencionado no conceito com o sentimento de prazer, poderemos também ter um meio de estabelecer uma conexão entre o juízo teleológico e o sentimento de prazer. Se quisermos, porém, prosseguir e investigar em que bases essa conexão é realmente possível, ela tem de ser tratada com mais cuidado e estabelecida com mais solidez.

\section{Proposta de um caminho por meio do qual pode ser encontrada a conexão entre o juízo teleológico e o sentimento de prazer}

Mas será que podemos contar com indicações oriundas do próprio Kant de modo que nossa proposta possa prosseguir com bases mais sólidas? O que temos então? Temos, em primeiro lugar, uma indicação de que esse caminho deve ser procurado pelo fato de Kant ele mesmo estabelecer essa conexão - entre a faculdade do juízo e a faculdade de sentir prazer e desprazer - ao tratar dos sistemas das faculdades da mente. Em segundo lugar, temos um apoio na referência ao fato de que realizar uma intenção gera o sentimento de prazer. Esse é o caminho que poderia ser investigado com mais cuidado, pois, ainda que o juízo teleológico por si só não traga consigo o pressuposto de que uma intenção foi realizada - ele pressupõe apenas o conceito de um fim - a realização da intenção, em contrapartida, pressupõe um conceito prévio que determina a ação, em outras palavras, a realização de uma intenção pressupõe o conceito de fim. A realização de uma intenção exige, então, algo mais, que não está contido no conceito do fim, exige a 
efetuação de um ato. Como o sentimento de prazer é resultante do ato intencional realizado, podemos por essa via, indireta, tentar resgatar para os juízos teleológicos uma conexão com o sentimento de prazer.

Mas como é mesmo que surge a necessidade de pensarmos as coisas em função do conceito de um fim?

O surgimento do conceito de fim no qual se funda o juízo teleológico é decorrente da necessidade de se atribuir à natureza, além da finalidade lógica e formal, própria dos juízos lógicos e estéticos, a finalidade material. Mas por que precisamos atribuir à natureza uma finalidade material? Poderíamos responder a essa pergunta da seguinte maneira: do mesmo modo que a necessidade da formação de conceitos levou à necessidade de se pressupor uma continuidade nas formas dos produtos da natureza de modo a que essa continuidade pudesse justificar a formação dos conceitos e leis empíricas, ou seja, levou à necessidade de se pressupor uma finalidade lógica; e do mesmo modo que o sentimento de prazer diante de certos objetos da natureza levou à necessidade de se investigar suas condições de possibilidade e a se pensar, então, numa compatibilidade possível entre a forma dos objetos e as nossas faculdades cognitivas, ou seja, levou à necessidade de se pressupor uma finalidade formal da natureza; assim, também, o fato de estabelecermos uma relação de meio e fim entre os produtos da natureza nos leva a pressupor uma finalidade material na natureza. Ou seja, a observação da natureza leva à percepção de que as relações entre seus produtos não se limitam apenas a uma relação de causalidade eficiente, mas exige também um outro tipo de causalidade, a causalidade final. Mas, o que é exatamente uma causalidade final? O que pode realmente ser um fim?

Ao longo de toda a analítica da crítica do juízo teleológico, Kant procura não só esclarecer esse conceito, mas também determinar o que, na natureza, pode ser considerado um fim. No entanto, o conceito de fim, não é um conceito do entendimento, como vimos, mas da razão, pois é a razão que procura pelos fins, pelas condições últimas etc. Mas, como a razão não tem relação direta com a sensibilidade, com o objeto dado, o conceito de fim permanece indeterminado, é um conceito problemático, como vimos. O conceito de fim serve muito mais para nos orientar quando temos de lidar com os produtos da natureza, especialmente quando a causalidade eficiente não basta, do que um conceito que serve para o reconhecimento de certos produtos como sendo finais. Desse modo, ao longo da analítica, Kant indica os diversos caminhos segundo os quais as coisas podem ser vistas como finais.

As coisas são vistas como finais umas em relação às outras. Nesse sentido podemos dizer com Kant que "os rios levam consigo, por exemplo, toda espécie de terras úteis para o crescimento das plantas ..."; que "nas terras frias a neve protege as sementes contra a geada;" ou que "facilita a sociabi- 
lidade humana (por meio dos trenós)" (CFJ: § 63, p.209-211; AA 05: 367369). Trata-se de uma finalidade externa ou relativa, pois, nesse caso, uma coisa nunca poderia ser considerada como sendo realmente final, já que a atribuição de finalidade à coisa sempre pode ser contestada: é sempre possível nos lembrarmos de plantas que crescem em regiões em que há poucos rios, ou em que não há rios de todo, ou da existência de sociabilidade onde não há neve, ou de situações em que a neve, em vez de ajudar, impede a sociabilidade, e assim por diante (Idem, ibidem).

Kant encontra, então, no conceito de organismo uma melhor orientação para dar conta da finalidade material da natureza. Por meio dele, o conceito de finalidade material ganha maior clareza. Uma das notas fundamentais que pertence ao conceito de organismo é da anterioridade do todo em relação às suas partes, o que não acontece quando pensamos as coisas como sendo o resultado de causas eficientes (CFJ: §65, p. 215; AA 05: 374). Assim, existem certos produtos que não podem ser concebidos como resultantes apenas de uma confluência de diferentes causalidades eficientes. Mesmo que possamos atribuir entre as partes de um todo relações de causalidade eficiente, elas não são suficientes para dar conta do objeto em seu todo. Para termos uma melhor compreensão de alguns seres encontrados na natureza temos de vê-los como se fossem produtos da arte, em que o todo é pensado de antemão e as partes são produzidas em função do todo previamente pensado.

Pensar a causalidade final da natureza em função do modelo da produção artística, ainda que seja mais satisfatório do que aquele em que a causalidade é vista apenas como o resultado de uma relação exterior entre as coisas da natureza deixa ainda a desejar porque nos leva necessariamente a ter de pressupor o artífice, que pensou na coisa antes de produzi-la. E se pensamos no artífice, o produto não é mais um produto da natureza, mas, do artista. Poderíamos alegar que o artífice é um ser da natureza e que nesse sentido o produto ainda é um produto da natureza. No entanto, o artífice pensado como um ser natural não produz objetos naturais, mas objetos que, enquanto produzidos por ele, são artísticos. Se aplicarmos esse modelo de produção à natureza, chegaremos à conclusão de que o seu produtor não poderia tampouco, ele mesmo, fazer parte da natureza, pois assim como o produto de um artífice não é mais natureza, mas arte, um produto natural teria de ser produzido por um ser que não fizesse parte da natureza, que não fosse um ser sensível, mas supra-sensível. Mas nesse caso, ainda que o produto fosse natural ele não seria originário da natureza.

No entanto, é na metodologia da crítica da faculdade do juízo teleológica, e não na analítica, que Kant vai encontrar uma solução mais satisfatória e mesmo definitiva para essa questão. Podemos encontrar no homem, enquanto ser moral, uma via por meio da qual seria possível resgatar para os 
juízos teleológicos sua conexão com a faculdade de sentir prazer e desprazer. Quando dizemos o homem como ser moral, queremos dizer um ser natural organizado cuja realidade, enquanto ser moral, não se esgota na natureza, mas é um ser cuja natureza traz consigo a faculdade da razão, um ser que pode colocar fins para si mesmo e que pode ultrapassar a natureza sensível e pensar a si mesmo contendo em si algo supra-sensível, ou seja, como um ser que pode se representar como sendo livre. As "leis morais têm como característica peculiar o fato de prescreverem incondicionalmente à razão algo como um fim, por conseguinte precisamente como é exigido pelo conceito de um fim. Por isso a existência de uma tal razão, que na relação final consigo mesma pode ser a lei suprema - por outras palavras, a existência de seres racionais sob leis morais - pode por isso ser pensada unicamente como fim terminal [Endzweck] da existência de um mundo" (CFJ: §87, p. 289-290; AA: 05:449). Assim, encontra-se no ser humano, enquanto ser moral, o fundamento absoluto, incondicionado, da finalidade da natureza.

Podemos dizer, ainda, que existe um ressoar, no final da metodologia, daquilo que Kant diz na Introdução publicada, a respeito do prazer causado pela realização de um fim. Segundo Kant, existe em nós uma faculdade de juízo que determina a priori para máximas práticas, "enquanto elas se qualificam para uma legislação universal uma complacência [satisfação] que tomamos lei para qualquer um ...." (CFJ: §42, p. 146; AA 05:300). O prazer resultante da ação de acordo com essa legislação chama-se sentimento moral (Idem, ibdem).

Uma analogia talvez torne mais claro o que está em questão aqui. Da mesma maneira que a relação entre a faculdade da imaginação e a do entendimento, quando estimulados pela forma de um objeto, estimulando-se mutuamente, gera um sentimento de prazer que tem sua origem a priori; assim também a razão pura ao determinar a vontade gera o sentimento moral, um sentimento que tem origem nas faculdades humanas, um sentimento que tem, portanto, uma origem a priori como o anterior. E na medida em que o sentimento de prazer estético é um prazer vivificador das faculdades do ânimo, assim também o sentimento moral não pode deixar de ser vivificador, e, portanto prazeroso. Pois, como acontece no prazer do juízo de gosto, trata-se no caso do sentimento moral, do acordo entre duas faculdades, razão e vontade, (ainda que talvez no sentimento moral haja um desacordo inicial, um desprazer em se abrir mão de uma inclinação para seguir a razão). Esse acordo gera um sentimento de respeito por nós mesmos enquanto seres que podem representar a lei (moral) e agem de acordo com ela, ou seja, de acordo com o que a razão exige. Ambos são sentimentos que nos remetem para alguma coisa que não é sensível, mas supra-sensível. No caso do prazer resultante do estímulo entre a imaginação e o entendimento, o supra-sensível é pensado como estando na natureza fora de nós, pois a 
imaginação apreende no fenômeno uma forma dada pela natureza, forma essa que é considerada como sendo final para as nossas faculdades cognitivas. No caso do sentimento resultante do agir moral, da determinação da vontade pela razão, o supra-sensível é pensado com estando em nós, na medida em que essa relação pressupõe a lei (moral) da razão e, com ela, a liberdade. Mas em ambos os casos, tanto estando fora de nós como estando em nós, trata-se de um supra-sensível que tem a ver com a natureza.

Que o homem, como ser moral e que traz em si algo de supra-sensível, tenha sido resgatado para justificar o fim terminal da natureza faz todo sentido. Mas a relação dos juízos estéticos com o supra-sensível ainda não faz sentido. Na verdade, nos referimos a isso rapidamente no início. A ideia de supra-sensível perpassa não só toda a CFJ, mas toda a filosofia crítica. O idealismo transcendental por distinguir fenômeno de coisa em si, pressupõe também que, ao pensarmos a coisa em si, pensamos algo supra-sensível. E os juízos estéticos, na medida em que dizem respeito a uma finalidade formal, pressupõem a coisa em si, a partir da qual essa forma se manifesta.

Um último ponto precisa ainda ser levado em consideração: se fomos bem sucedidos ao indicar um caminho por meio do qual os juízos teleológicos podem ser conectados com o sentimento de prazer e de desprazer, precisamos também chamar a atenção para o fato de que relação que esses juízos têm com o sentimento de prazer é diferente daquela que os juízos estéticos têm com o mesmo sentimento. Enquanto nos juízos estéticos esse sentimento fundamenta e determina os juízos de gosto, no caso dos juízos teleológicos o sentimento de prazer é resultante da realização de uma intenção, um fim que foi antes pensado por meio da razão.

BUENO, Vera Cristina de Andrade. Teleological reflexive judgement and its relationship with the feeling of pleasure and displeasure. Trans/Form/Ação, São Paulo, v.32(1), 2009, p.73-84.

- ABSTRACT: After establishing a general connection between the power of judgment and the feeling of pleasure and displeasure in the "First Introduction" to the Critique of the Power of Judgment, in the "Published Introduction", Kant proceeds to restrict this connection gradually to aesthetic judgments and to judgments that deal with the systematization of nature. This restriction leaves teleological judgments out of the formerly established general connection. The aim of the article is to give an account of the necessary procedures that had to be adopted by the reader of Critique of the Power of Judgment in order to maintain the connection between teleological judgments and the feeling of pleasure, namely a connection that, in principle, all reflecting judgments were meant to have.

- KEYWORDS: Kant; reflecting judgment; teological judgment; finality principle; feeling of pleasure and displeasure; moral action. 


\section{Referências bibliográficas}

KANT, Immanuel. Crítica da razão pura. Lisboa: Fundação Calouste Gulbenkian, 1994.

Crítica da faculdade do juízo. Rio de Janeiro: Forense Universitária, 1993.

TERRA, Ricardo (ed). Duas introduções à Crítica do juízo. São Paulo: Iluminuras, 1995. 